\title{
Quantitative evaluation of Serum Progesterone levels in the three trimesters of pregnancy in Albino rat.
}

\section{*11AGOREYO FO; ONWEGBU VI}

\author{
Department of Physiology, School of Basic Medical Sciences, College of Medical Sciences, University of Benin, Nigeria \\ Agoreyo F.O. Department of Physiology, School of Basic Medical Sciences, College of Medical Sciences, University of Benin \\ Email: agoreyofo@yahoo.com
}

KEY WORDS: Progesterone, trimester, pregnancy ,albino rat.

\begin{abstract}
Progesterone is a major hormone of pregnancy. Evidence suggests that without luteinizing signal, the corpus luteum may be dysfunctional and subsequent progesterone secretion may be abnormal which could lead to decrease in implantation and thus decrease in viability of pregnancy. The aim of the study was to determine if there was an increase in progesterone level at different trimesters of pregnancy in wistar rats. Twenty female albino rats were categorized into four different groups of five rats each. Group one (non-pregnant rats) served as the control. Groups two, three and four were pregnant rats in days 5, 12 and 19 corresponding to first, second and third trimesters of pregnancy respectively. Blood samples collected from the four groups were subjected to ELISA method for the assay of serum progesterone levels. There were statistically significant increases in the second $(25.62 \pm 3.74 \mathrm{pg})$ and third $(36.36 \pm 1.17 \mathrm{pg})$ trimesters when compared with non pregnant wistar rats $(5.70 \pm 1.35 \mathrm{pg})$. The increase observed in the first trimester was not statistically significant. (C) JASEM
\end{abstract}

\section{http://dx.doi.org/10.4314/jasem.v19i1.10}

\section{Introduction}

Pregnancy is the state of carrying a growing embryo or fetus inside the uterus of a woman or female animal carrying unborn offspring inside her womb from fertilization to birth. It starts when a male's sperm fertilizes ovum and implants into the lining of the uterus. In pregnancy, there are changes in a woman's normal hormone patterns.

In many societies, medical or legal definition, human pregnancy is somewhat arbitrarily divided into three trimester periods (Olatunji-Bello II et al., 2001) as a means to simplify reference to the different stages of prenatal development. During pregnancy, the placenta produces large quantities of estrogen and progesterone. Estrogen and progesterone stimulate the endometrium to support fertilized egg if pregnancy occurs.

Progesterone during pregnancy is primarily produced by the placenta. In women, progesterone levels during the preovulatory phase of the menstrual cycle is relatively low, rises after ovulation and are elevated during the luteal phase (Farage et al .,2009). Progesterone levels tend to be $<2 \mathrm{ng} / \mathrm{ml}$ prior to ovulation and $>5 \mathrm{ng} / \mathrm{ml}$ after ovulation. If pregnancy occurs, human chorionic gonadotropin is released maintaining the corpus luteum, allowing it to maintain levels of progesterone. At around 8 weeks the placenta begins to produce progesterone in place of the corpus luteum. This process is called the luteal-placental shift (Chabbert et al., 2007). Progesterone function is to inhibit the smooth muscle in the uterus from contracting and decreasing prostaglandin formation, both of which allow the foetus to grow with the expanding uterus. It also serves as a precursor to most steroid hormones(Bowen, 2000).

\section{MATERIALS AND METHODS}

Test subjects: Twenty female albino rats and six male albino rats, with initial weight of $165-180 \mathrm{~g}$ were purchased from the animal house of the Department of Animal and Environmental Biology, University of Benin, Benin city, Edo state, Nigeria. The twenty female rats were housed in wooden cages in groups of five (5) rats per group while the 6 male rats were kept in a separate cage in the Animal House facility of the Department of Animal and Environmental Biology (AEB), Faculty of Life Science, University of Benin, Benin City. They were acclimatized for seven days. A 12-hours photoperiodic light : dark cycle was maintained. They were fed with growers mash (produced from Ewu flour mill, in Edo state) and water adlibitum until a weight between 210-290g was achieved. 
All procedures adopted complied with the International Guidelines for the Care and Use of Laboratory Animals as stated by the Ethical Committee, Faculty of Life Sciences, University of Benin, Benin City, Edo State, Nigeria.

The female rats in estrous in three of the cages were mated by introducing two (2) male rats to the separate cages containing five (5) female rats each overnight. The following morning, the female rats were checked for signs of pregnancy by confirming presence of sperm in vagina smears or cervical plug.

The female rats were divided into four groups; the non pregnant group serving as control; the pregnant first trimester, second trimester and third trimester groups.

At day 5, 12 and 19 corresponding to first, second and third trimester periods respectively, the animals were anaesthetized and blood samples were collected from the abdominal aorta using a $5 \mathrm{ml}$ syringe each. The blood sample was immediately transferred into a non EDTA bottle for recovery of serum. The same procedure was undertaken for the control (non pregnant) group.
Statistical analysis of results Statistical analysis was performed using the computer program GRAPHPAD INSTAT. All data were expressed as Mean + SEM. All data were analyzed by a single factor design ANOVA. Statistical significance was accepted at ( $\mathrm{p}$ $<0.05)$.

\section{RESULTS}

Table1: Shows the level of progesterone in the stages of pregnancy in pregnant and non-pregnant rats (control)

Values are represented as mean \pm S. E. M

\begin{tabular}{ll}
\hline Stages of Pregnancy & Values (ng) \\
\hline Control & $5.70 \pm 1.35$ \\
First Trimester & $11.78 \pm 2.83^{\mathrm{b}}$ \\
Second Trimester & $25.62 \pm 3.74^{\mathrm{a}}$ \\
Third trimester & $36.36 \pm 1.17^{\mathrm{a}}$ \\
\hline
\end{tabular}

$\mathrm{a}-$ indicate that it was statistically significant when compared with control $(\mathrm{p}<0.05)$

$\mathrm{b}$ - indicate that it was not statistically significant when compared with control $(\mathrm{p}>0.05)$

$\mathrm{n}-5$ per group

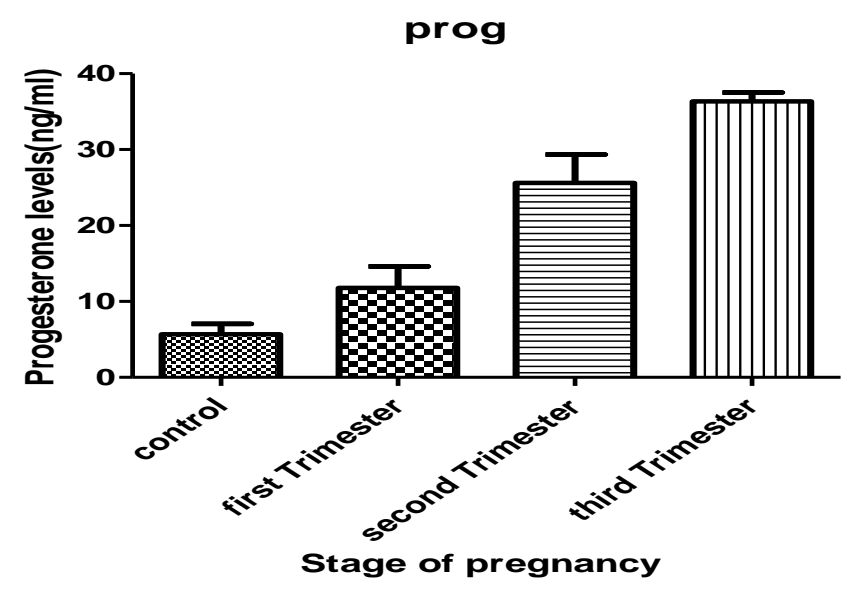

Fig.1: A bar chart showing a gradual increase in progesterone level at different stages of pregnancy.Values are presented in mean \pm S.E.M with $n=5$ per group

\section{DISCUSSION}

Progesterone is a sex hormone found mainly in female and it is one of the dominant hormone during pregnancy. In our result, there was an increase in progesterone level in every stages of pregnancy. Table1 and Figure 1 shows there were increases of progesterone levels in the first trimester $(11.78 \pm 2.83 \mathrm{ng})$, second trimester $(25.62 \pm 3.74 \mathrm{ng})$ and third trimester $(36.36 \pm 1.17 \mathrm{ng})$ when compared with control $(5.70 \pm 1.35 \mathrm{ng})$. This was similar to the observed statistically significant increases in the level of estrogen, another pregnancy hormone in pregnant female wistar rats ( Agoreyo and Okeke 2014).

The increase in progesterone level at the different stages of pregnancy is as a result of converting the endometrium to its secretory stage to prepare the uterus for implantation (Guyton and Hall, 2006). It also affect vaginal epithelium and cervical mucus, making it thick and impenetrable to sperm. During implantation and gestation, it decreases the maternal immune response to allow for the acceptance of the pregnancy and it also decreases contractility of the 
uterine smooth muscle (Bowen, 2000). Therefore the progressive increase in the level of progesterone during the stages of pregnancy shows that progesterone plays a major role in the development of the foetus and it is thus sometimes called the "hormone of pregnancy" (Bowen, 2000).

Conclusion: In our study, it was concluded that progesterone increases at different stages of pregnancy and that at the third trimester the progesterone level was highest.

\section{REFERENCES}

Agoreyo F.O. and Okeke O.G. (2014) Quantitative Evaluation of Serum Oestrogen levels in the three Trimesters of Pregnancy in Albino rat. NISEB JOURNAL 14: 98 - 100.

Bowen, R (2000) “Placental Hormones". Retrieved 2008.
Chabbert, B. N., Pintiaux, K. A., Bouchard, P (2007). Effects of the progesterone receptor modulator VA2914 in a continuous low dose on the hypothalamic-pituitary-ovarian axis and endometrium in normal women: a prospective, randomized, placebo-controlled trial. Journal of Clinical Endocrinology Metabolism.92:3582.

Farage, M. A., Neil, S and Maclean, A.B. (2009). Physiological changes associated with the menstrual cycle; a review. Obstetrical and Gynecological Survey. 64(1): $58-72$

Guyton and Hall (2006).Text book of Medical physiology. $11^{\text {th }}$ ed. Endocrinology. Pp 10181039.

Olatunji-Bello II, Nwachukwu D. and Adegunloye BJ.(2001). Blood pressure and heart rate changes during pregnancy in fructose-fed SpragueDawley rats. Afr J Med Med Sci. 30(3):187-90. 